\title{
Construction and Analysis on the Hybrid System Test Bench of New Energy Bus
}

\author{
Kun ZHOU², Qiu-Lin SUN ${ }^{2}$, You-Ming TANG ${ }^{*}, 1,2$, Gui-Bin SUN ${ }^{1}$, Shui-Ting \\ ZHOU $^{1}$, Yi ZHANG ${ }^{1}$ and Yuan-Wei ZHANG ${ }^{1,2}$
}

1Fujian Institute of New Energy Vehicles and Safety Technology, Xiamen University of Technology, Xiamen, Fujian, 361024, P.R. China

2Fujian Fugong Power Technology Co, Ltd, Xiamen, Fujian, 361024, P.R. China

Keywords: ISG system, Hybrid system, Test bench, New energy bus.

\begin{abstract}
There is high market demand for new energy vehicles. And the driving system of new energy bus gets improved day by day. Within the performance studies on core components such as electric machinery, controller, battery and gearbox and within the vehicle system performance matching and conformity, it is an important part to accurately and quickly construct a test bench of the new energy bus hybrid system. To achieve ideal results of the bench test, the paper probes into the test objects, the test items, the site layout and technology assessment and others, and has taken every relevant factors into consideration.
\end{abstract}

\section{Background}

Since 21st century the hybrid system has made continuous extension and its techniques including oil gas, gas-electric and gas-electric and others have been brought gradually into market. The paper mainly discusses the new energy bus hybrid system which is divided into BSG system and ISG system as different positions of the generators.

BSG hybrid system means linking generator and engine through the integration of the belt drive and mechanism in the front end of the engine, which replaces the former generator and achieves integration of hybrid system. ISG system driver modes mainly includes following four kinds: pure electric-operation mode, electric-operation in series mode, hybrid drive in parallel mode, and pure engine-driven mode [1]. The brake system modes mainly are double-motors braked mode and single-motor braked mode.

Nowadays the mixed coaxial direct drive occupies main hybrid system market. ISG system has solved the problems that the belt grinds early and that the crankshaft bearings of engine have eccentric wear, meantime it owns high saving rate of fuel consumption and good stability. Compared with BSG system, ISG system has following advantages: various working modes, high stability, high reliability, high integration, efficient brake recovery, low-energy driver and convenient maintenance [2].

The paper studies ISG system and BSG system to build hybrid system bench and discusses building plans.

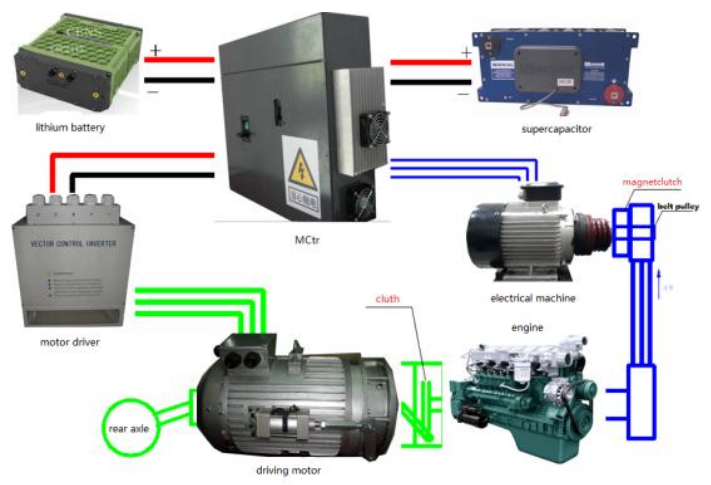

Figure 1. BSG Sketch 


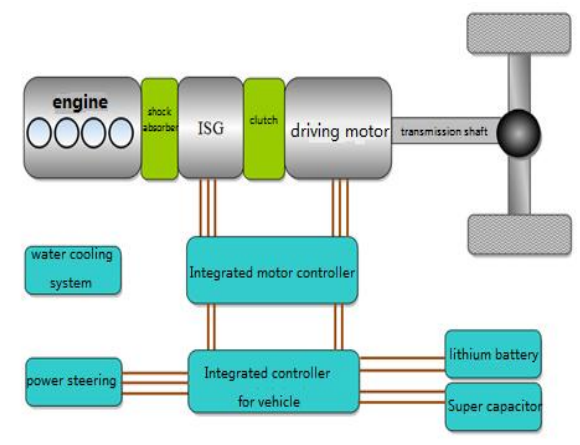

Figure 2. ISG Sketch

\section{Preparations for Building Benches}

Building hybrid system benches are time-consuming and energy-consuming projects, which include previous preparation, project development, project acceptance. In the early stage of hybrid system bench construction, we should collect data and consider equipment utilization ratios, equipment price, importance, work confidentiality and overall plan. Besides, we should ascertain the test bench target and its relevant information and various parameters. Manufacturers generally aim at driving systems under multiple spectrum to build hybrid products. Therefore, we need to synthetically consider kinds of parameters of spectrum and take the maximum speed, torque and power as reference. When choosing dynamometer, its spectrum parameters needs to be enveloped [3]

\section{Principles of Bench Construction Selection}

As for manufacturers without developing engines, they mainly study the integration effects among engine and motor, controller, transmission. When selecting equipment, we should consider parameters like testing precision and response time which will directly affect the data or frequency collection.

\section{Dynamometer Selection}

The power and speed of dynamometer can be determined by combing the motor and engine spectrum in the early stage of project. When selecting dynamometer, we try to envelope all tested products into dynamometer curve [4].

1) According to the characteristics of motor peak, the maximum output power changes as speed differs before rated speed, but peak torque basically remains invariant. The maximum output power remains same with the change of speed after rated speed, but peak torque gradually decreases.

2) Formula of Power Torque Speed.

$\mathrm{P}=\mathrm{T} * \mathrm{~N} / 9550$

Among them: P--- Power; T--- Torque; N--- Speed

Therefore the following two points need evaluating to judge whether the tested product is within dynamometer curve or not. 1) To analyze whether torque is lower than the peak torque before rated speed. 2) To analyze whether peak torque power of the tested product is lower than peak power at maximum speed. 


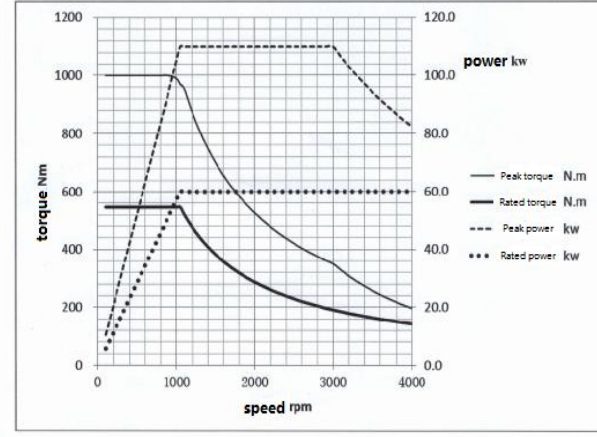

Figure 3. The Motor Graph

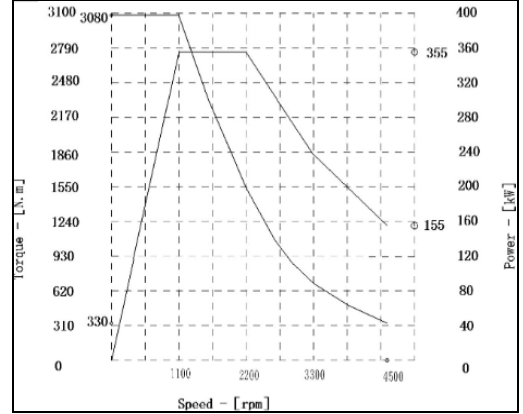

Figure 4. A Brand Dynamometer Graph

\section{Torque Flange Selection}

When selecting torque flange we should pay attention to the following three points. 1) The speed of torque flange and the choice of torque; 2) The precision choice; 3) The linking methods.

\section{Dynamometer Frequency Converter Selection}

Before selecting dynamometer frequency converters we firstly need to consider the ways to use electricity of bench. In general there are two modes showed in table 1.

Table 1. Electric Way of Bench

\begin{tabular}{|c|l|l|}
\hline Mode & Directly Connected with Three-phase & \multicolumn{1}{c|}{ Share Direct Co Bus } \\
\hline Instruction & $\begin{array}{l}\text { The input source of the transducer of the } \\
\text { dynamoeter is three-phase alternating current. }\end{array}$ & $\begin{array}{l}\text { The input source of the dynamometer is DC } \\
\text { power, which is supplied by the DC regulated } \\
\text { power supply. }\end{array}$ \\
\hline $\begin{array}{c}\text { Schematic } \\
\text { Diagram }\end{array}$ & $\begin{array}{l}\text { Dc regulated power supply } \\
\text { Features }\end{array}$ & $\begin{array}{l}\text { 2. Through the transducer, the electric directly } \\
\text { backs to the power grid which has impact on } \\
\text { the power grid. }\end{array}$
\end{tabular}

When choosing dynamometer converters we should think the electricity modes whose maximum input voltage and maximum input current depend on maximum voltage and maximum current, and whose response time depends on the response time of tested motor controller.

\section{Direct-Current and Stable-Voltage Power Supply Selection}

Direct-current and stable-voltage power supply is also called battery simulator selection which is taken into consideration together with the ways to use electricity of bench. Both single-channel direct-current and stable-voltage power supply and double-channels one are the energy-feedback type. When choosing direct-current and stable-voltage power supply we must consider the impact on grid from energy-feedback. According to the national standard GB/T 14549-93, there are two key requirements about implanting harmonic into grid.

1) The power factor of direct-current and stable-voltage power supply is less than 0.99 . 
2) The current distortion is less than $5 \%$.

If the above two requirements fail to meet, the grid frequency can be affected when the system gives back energy to the grid, which makes the grid unstable even shows a sudden power outage.

\section{Regulating System Selection}

The main regulating equipments of bench system are engine fuel, engine cooling water, engine oil, transmission oil and motor cooling water temperature control systems, all of which are controlled by temperature. Besides, although the car engine and gearbox have cooling device, the changes of temperature will directly affect the test results. And it is suggested to adapt separate regulation system.

\section{Test Items}

Hybrid system platform construction can test engine and gearbox, however the main purpose of construction is to study the integration effects of driving system and the working efficiency and running state of every components under different running modes. Therefore, the main basis of test standards is GB/T18488, and simulation road bases on related standards of pure electric or hybrid [5]. To see table 2 .

Table 2.Test Items and Test Standards

\begin{tabular}{|c|c|}
\hline Test Items & Test Standards \\
\hline \multirow{4}{*}{$\begin{array}{l}\text { A. Test items of drive motor: voltage fluctuation } \\
\text { and peak power measurement, system highest } \\
\text { working speed and overspeeding test, the motor } \\
\text { torque characteristics and efficiency test (electric } \\
\text { high efficient area test); motor stalling a } \\
\text { locked-rotor torque and current overload test, the } \\
\text { motor and its controller test, renewable energy } \\
\text { feedback test, the protective function of motor } \\
\text { controller, electrical power generation efficiency } \\
\text { test (feeding high efficient area test) }\end{array}$} & $\begin{array}{l}\text { GB T 19753-2005 Light hybrid electric vehicle Energy } \\
\text { consumption Test method }\end{array}$ \\
\hline & $\begin{array}{l}\text { GB T 19754-2005 Heavy-duty hybrid electric vehicle Energy } \\
\text { consumption Test method }\end{array}$ \\
\hline & $\begin{array}{l}\text { GB T 18488.1-2015 Driving motor system for electric vehicle } \\
\text { Part 1: Technical conditions }\end{array}$ \\
\hline & Driving motor system for electric vehicle \\
\hline \multirow{2}{*}{$\begin{array}{l}\text { B. Hybrid powertrain test project: hybrid } \\
\text { powertrain test loop conditions, maximum output } \\
\text { speed, hybrid powertrain hybrid assembly } \\
\text { maximum output torque, a hybrid system } \\
\text { reliability test }\end{array}$} & Hybrid electric vehicle safety requirements \\
\hline & Hybrid electric vehicle: Dynamic performance \\
\hline \multirow{2}{*}{$\begin{array}{l}\text { C. Engine test project: engine speed } \\
\text { characteristic test energy consumption, } \\
\text { mechanical loss power test }\end{array}$} & Electric vehicles: Dynamic performance test \\
\hline & $\begin{array}{l}\text { BT 18386-2005 Hybrid electric vehicles: Energy consumption rate } \\
\text { and driving range test method }\end{array}$ \\
\hline
\end{tabular}

\section{Laboratory Arrangements and General Requests}

Hybrid system laboratory arrangements should take the electricity utilization, water usage, air conditioning, ventilation, fire protection, transportation, vibration reduction, noise reduction and exhaust and other factors into consideration [6].

1) Vibration reduction: Hybrid system tests makes high speed and vibration. Running engine also makes bigger vibration. In general dynamometer is fixed into large iron floor with T-slot, and damping spring is used to decrease vibration under the iron floor. The pits fits the land building.

2) Noise reduction: That dynamometer runs at high speed will produce noise. We need to use some sound insulation and noise reduction measures about walls, doors and windows.

3) Electricity Usage: Dynamometer inverter and battery simulator are high-power electrical 
appliances, therefore we need to offer high power electricity to the power point.

Given power dynamometer is W1, and maximum power for all tested prototype is W2, according to the following two modes, the choices of dynamometer power consumption and breakers are shown in table 3.

4) Water Usage: Dynamometer are usually air cooling as well as water cooling. Many systems are water cooling, so the laboratory needs to circulate cooling water for the use of motor cooling system. At the same time, we also need to consider water temperature and flow requirements of the main equipment. In general, every test temperature is shown in the following table, and the equipment flow is related to its peak power.

Table 3.Power Consumption of Dynamometer and Breaker Selection

\begin{tabular}{|c|c|c|}
\hline Mode & Directly Connected with Three-phase & Common Direct Current \\
\hline Instruction & $\begin{array}{l}\text { The input source of the dynamometer is } \\
\text { three-phase alternating current. }\end{array}$ & $\begin{array}{l}\text { The input source of the dynamometer is DC power, } \\
\text { which is supplied by the DC regulated power } \\
\text { supply. }\end{array}$ \\
\hline \multirow{3}{*}{$\begin{array}{l}\text { Schematic } \\
\text { Diagram }\end{array}$} & \begin{tabular}{|l|l|l} 
Dc regulated power supply & \\
\end{tabular} & Dc regulated power supply \\
\hline & $\uparrow \uparrow$ & $\uparrow \begin{array}{llll} & \uparrow & \uparrow & \uparrow \\
& \downarrow & \downarrow\end{array}$ \\
\hline & The inverter & The inverter \\
\hline $\begin{array}{l}\text { Electricity } \\
\text { Description }\end{array}$ & $\begin{array}{l}\text { The electric which is supplied by the } \\
\text { dynamometer and the sample directly } \\
\text { goes to the grid and supplies for other } \\
\text { devices. }\end{array}$ & $\begin{array}{l}\text { The electric is consumed inside the system which } \\
\text { is through DC regulated power supply. }\end{array}$ \\
\hline Features & $\begin{array}{l}\text { The power consumption of a single } \\
\text { station is large, and the current of the } \\
\text { circuit breaker is also large. }\end{array}$ & $\begin{array}{l}\text { The power consumption of a single station is } \\
\text { small, and the current of the circuit breaker is also } \\
\text { small. }\end{array}$ \\
\hline $\begin{array}{l}\text { Platform using } \\
\text { power }\end{array}$ & $\begin{array}{l}\text { 1.Mechanical work to the power } \\
\text { efficiency of } 0.8 \\
\text { 2. bench efficiency loss rate of } 0.3 \\
\text { 3.Efficiency=electric power-feedback } \\
\text { power * efficiency loss rate } \\
\text { W loss=W2 }\end{array}$ & $\begin{array}{l}\text { 1. Mechanical work to the power efficiency of } 0.8 \\
\text { 2. bench efficiency loss rate of } 0.3 \\
\text { 3. Efficiency = electric power - feedback power * } \\
\text { efficiency loss rate } \\
\text { W loss=W2/0.8-W2* (1-0.3) }\end{array}$ \\
\hline Circuit Breaker & I broken=W1 $/ 0.8$ & I broken $=W 2 / 0.8$ \\
\hline
\end{tabular}

Table 4. Cooling water requirements of Main Equipment

\begin{tabular}{|c|c|c|c|c|c|}
\hline & Cooling Medium & $\begin{array}{c}\text { Input Water } \\
\text { Temperature }\end{array}$ & $\begin{array}{c}\text { Output Water } \\
\text { Temperature }\end{array}$ & $\begin{array}{c}\text { Cooling } \\
\text { Power }\end{array}$ & Flow \\
\hline Dynamometer & Water cooling & $<60^{\circ} \mathrm{C}$ & $>100^{\circ} \mathrm{C}$ & --- & $\geq--$ \\
\hline Motor & Water cooling & $<60^{\circ} \mathrm{C}$ & $>85^{\circ} \mathrm{C}$ & --- & $\geq--$ \\
\hline Motor Controller & Water cooling & $<65^{\circ} \mathrm{C}$ & & --- & $\geq-$ \\
\hline Engine & Water cooling & $<83^{\circ} \mathrm{C}$ & $>105^{\circ} \mathrm{C}$ & --- & $\geq-$ \\
\hline
\end{tabular}

In addition, we should take arrangements of the fuel supply system, the engine's intake air conditioning, the engine exhaust system and the whole room ventilation or air conditioning system into consideration. It is also highly required to solve vibration and noise. 


\section{Hybrid Bench Basic Function Requirements Instructions}

Built hybrid bench has the following basic functions:

1) It can adjust to the working mode of manual transmissions and automatic transmission (AMT, AT, CVT, DCT and general hybrid transmission).

2) The platform system has the inertia simulation of the whole vehicle, the simulation of the road resistance, the simulation of the mechanical braking force and the simulation of the automatic driving functions.

3) Bench system can adjust to recycling energy of hybrid energy braking systems and studying power allocation strategies. The brake system should fit two kinds structure forms in series or in parallel from the moto feedback energy $\mathrm{r}$ brake and mechanical brake.

4) The system can simulate the using electricity order of the whole vehicle, including the use of low-voltage power system and the use of high voltage system.

5) The protection of bench system should suit parking ways of hybrid power train and working ways of pure electric mode and other hybrid systems, which can set protection strategies of current and voltage by usingcurrent and voltage measurement parameters.

6) In the dynamic model it can achieve "time - speed" closed-loop control; it also can control the speed of opening loops (users set accelerator pedals, the opening of brakes and the time of shifting gears before tests) to reappear torque and speed of the tested vehicle in test bench.

7) The dynamic parameters of working condition can be input easily by users, for example, users can set different rolling resistance coefficient, relative wind speed, slope and bend coefficient that reflect road conditions; and users can set entire vehicle quality, radius of the tire, windward area, and unexisted inertia parameters that reflect the status of the vehicle condition; and users can set operating conditions such as vehicle starting, accelerating, uniform, sliding, decelerating, braking, the start point and end point of parking.

8) There is common vehicle driving cycles in the system. If the operating mode cycle, defined by users, can create and lead in controlling systems by simple files like Excel, the system can run according to the defined control system of powertrain test bench.

9) Bench can timely measure and store the operation data of the powertrain system including rotational speed, torque, fuel consumption, voltage, current and the pedal position, block information and some command data of the platform and others, which can be obtained by CAN protocol at the same time.

\section{Conclusions}

To build the hybrid system of passenger cars, we are supposed to understand the information of the test object, test content and support conditions etc. In this paper, we mainly discuss the preparation of the hybrid system, the main equipment selection criteria, the use of electricity and other aspects of the discussion rather than the battery test because of its high requirements to exam construction and fire protection. At the same time, EMC test, due to the high construction cost and low utilization rate, is suggested to outsource test, which is not explored in this paper either.

\section{Acknowledgements}

This study was financially supported by the Research and Development Project of State High Technology of China ('863 Project', 2012AA111105) and the Fujian Science \& Technology Project of China (2016H2003).

\section{References}

[1] Ye Xianjun et al. Han Zhao, Bingli Zhang and Xizhen Wang. The Parameters Design and Experimental Study for the Powertrain of BSG Hybrid Electric Car[C], Automobile Technology , 
2008.

[2] Wu Qitang, Powertrain System of New Energy Vehicle at Home and Abroad [J], Beijing: State Administration of Machinery Industry, 2009.

[3] Yang Yajuan, Han Zhao and Maofei Zhu, A Study on the Control Strategy for Maximum Energy Recovery by Regenerative Braking in Electric Vehicles [J], Automotive Engineering, 2013.

[4] Gao Meng, Ziming Liu, Research on Driving Resistance Simulation System by using Automobile Chassis Dynamometer[J], Vehicle \& Power Technology,2012.

[5] Liang Jingjing, and Jiang Zhishen, Analysis on Chinese and European New Energy Vehicle Market Entry Certification System [J], automotive technology research center of China, 2013.

[6] Sun Xiaoxin, Brief Analysis on Disciplines Structure of State Key Lab [J], scientific research regulation, 2008. 